\title{
Inhibitory Reflex during Bronchoconstrictions Induced by Histamine and Ascaris Suum Antigen
}

\author{
Miwa Misawa, Yoshinori Takahashi, Junzo Kamei ${ }^{1}$ and Tomokazu Hosokawa ${ }^{1}$ \\ Departments of Applied Pharmacology and 'Pharmacology, School of Pharmacy, Hoshi University, \\ 2-4-41 Ebara, Shinagawa-ku, Tokyo 142, Japan \\ Received July 15, 1991 Accepted December 24, 1991
}

\begin{abstract}
We investigated the involvements of sympathetic and nonadrenergic nervous systems in the inhibitory reflex following bronchoconstriction in dogs. Inhalations of a $0.00125 \%$ solution of histamine and Ascaris suum antigen ( $3 \mathrm{mg}$ protein) to the bronchial side induccd reflex tracheal constriction following bronchoconstriction. An intra-arterial infusion of $5 \mu \mathrm{g} / \mathrm{min}$ of atropine to the tracheal site changed the reflex tracheal constrictions by histamine and antigen inhalations into tracheal dilatations. The reflex tracheal dilatations were abolished by the combination of intra-arterial propranolol $(100 \mu \mathrm{g})$ and transections of both the bilateral superior laryngeal nerves and the spinal cord at the $\mathrm{C}_{1}$ level. The reflex tracheal constrictions induced by histamine and antigen inhalations were increased with $100 \mu \mathrm{g}$ propranolol. Furthermore, the reflex tracheal constrictions were enhanced by the combination of $100 \mu \mathrm{g}$ propranolol and transection of the spinal cord. These findings indicate that during the constriction of the bronchial smooth muscle, not only a reflex tracheal constriction mechanism but also one of reflex dilatation operates and that the latter reflex response may be mainly mediated by the sympathetic nerves, with partial involvement of the nonadrenergic nerves. This inhibitory reflex may attenuate asthmatic bronchoconstriction.
\end{abstract}

Several studies have reported the role of the vagal reflex in the airway constriction induced by histamine or antigen inhalations $(1-9)$. Hosokawa et al. (10) showed that the vagal reflex constriction of airways results from some complex effects that may be mediated by several sensory receptors in the airways. Stimulations of pulmonary irritant receptors and C-fiber endirgs induce a vagal reflex bronchoconstriction $(11,12)$. By contrast, the activation of stretch receptors by transient inflation of the lungs causes a reflex airway dilatation (10). Bartlett et al. (13) reported that the activity of airway stretch receptor increases during tracheobronchial constriction. Furthermore, Widdicombe and Nadel (14) suggested that airway stretch receptors could moderate the bronchoconstriction induced by stimuli like hypoxia and hypercapnia. However, the efferent pathway of the inhibitory reflex induced by activation of stretch receptors is still unknown.

Cabezas et al. (15) found that stimulation of sympathetic nerves inhibits bronchoconstriction. McCulloch et al. (16) reported the existence of an adrenergic-mediated bronchodilatatory reflex mechanism. It has been previously demonstrated that reflex tracheal dilatation caused by lung inflation may be mediated by adrenergic innervation and partly by nonadrenergic innervation (17). In the present study, therefore, to confirm the involvements 
of sympathetic and nonadrenergic nerves in the inhibitory reflex following histamine- and antigen-induced bronchoconstrictions, we determined if reflex tracheal dilatation occurs during bronchoconstriction and investigated the intervention of these nerves in the reflex tracheal constriction induced by bronchoconstriction.

\section{MATERIALS AND METHODS}

Experiments were performed with a preparation that could be used to evaluate the vagal reflex-induced responses of the airway, as described previously (10). Male mongrel dogs weighing $8-14 \mathrm{~kg}$ were lightly anesthetized with an i.m.-injection of ketamine hydrochloride $(10 \mathrm{mg} / \mathrm{kg})$. The cervical trachea was transected at about $7 \mathrm{~cm}$ caudal to the larynx with the membranous wall left intact. Care was taken not to obstruct the recurrent laryngeal nerves. The membranous wall at the transected site was ligated with a thread to interrupt blood flow passage across the wall. A tracheal cannula was inserted into the caudal side of the transected trachea. The animals were immobilized with decamethonium bromide (initial dose of $0.4 \mathrm{mg} / \mathrm{kg}$, i.v., and supplemental doses of $0.2 \mathrm{mg} / \mathrm{kg}$, i.v., every hour) and ventilated with room air by an artificial respirator (Natsume, $\mathrm{KN}-50$ ) at a frequency of 20 breaths $/ \mathrm{min}$. End-tidal concentrations of $\mathrm{CO}_{2}$ and $\mathrm{O}_{2}$ were continuously monitored with an expired gas monitor (San-Ei, 1H21), and they were maintained at optimal ventilation levels of $3.5-4.0 \%$ and $16.5-17.5 \%$, respectively, under resting conditions. The left femoral artery was cannulated, and the portion on which surgery was performed was treated with $1 \%$ procaine hydrochloride. The systemic arterial blood pressure was measured through the catheter connected with a pressure transducer (Nihon Kohden, MPU-0.5). The heart rate was monitored with the tachometer (Nihon Kohden, RT-5) using the systolic blood pressure as the trigger.

Responses of the bronchial musculature were measured by a modification of the Konzett-Rössler method (18). The lungs were ventilated at a fixed volume of air under a constant pressure $\left(10 \mathrm{cmH}_{2} \mathrm{O}\right)$, and the ventilation overflow was measured using a pneumotachograph (Nihon Kohden, MFP-1T) as an index of the change in bronchial responses. Responses of the tracheal musculature were measured as changes in the intratracheal pressure of an air-filled balloon introduced into the rostral side of the transected trachca using a pressure transducer (Nihon Kohden, LPU-0.1). The initial intraluminal pressure of the balloon was adjusted to 50 $\mathrm{mmH}_{2} \mathrm{O}$. In this preparation, the upper tracheal response was estimated fully as the reflex induced by activation of sensory receptors in the bronchus (10). The bilateral recurrent laryngeal nerves were cut beforehand in all animals so that efferent parasympathetic pathway to the upper trachea is only via the bilateral superior laryngeal nerves.

To administer drugs directly to the upper tracheal site where the reflex-induced tracheal responses were measured, we used the in situ technique for perfusion of the upper trachea, as described previously (19). Two arms of a Y-shape cannula were inserted to the bilateral cranial thyroid arteries, and the arterial blood from the right femoral artery was perfused into the cranial thyroid arteries via a peristaltic pump (Tokyo Rikakikai, MP-1011) at a constant flow. The perfusion rate was adjusted at the beginning of each experiment so that the perfusion pressure was approximately equal to the systemic arterial blood pressure. Just before starting the perfusion, the animal was given heparin sodium $(700$ units $/ \mathrm{kg}$, i.v., and maintained by $300 \mathrm{units} / \mathrm{kg} / \mathrm{hr}$, i.v.).

Experiments lasted about four hours at the longest. Throughout each experiment, the corneal reflex had disappeared, and systemic blood pressure, heart rate and $\mathrm{CO}_{2}$ and $\mathrm{O}_{2}$ levels in expired gas were almostly stable under resting conditions.

Drugs used were histamine dihydrochloride (Wako Pure Chemicals), propranolol hydrochloride (Inderal, Sumitomo Chemical Indus- 
try) and atropine sulfate (Tokyo Kasei). All doses were expressed in terms of the base. All drugs were dissolved or diluted in saline solution, and they were close-intra-arterially injected into the rubber tubing just before the $\mathrm{Y}$-shaped cannula.

Ascaris summ antigen was prepared with veronal-buffered saline according to the previous report (7). In the experiment of antigen inhalation, dogs that showed a positive result with the antigen solution at concentrations below $10^{-5} \mathrm{~g}$ protein $/ \mathrm{ml}$ in the skin test were used as naturally sensitized dogs. Ascaris suum antigen inhalation was carried out only once in each dog.

The results shown in the figures are expressed as mean values \pm S.E. Statistical analyses were made by Duncan's test.

\section{RESULTS}

\section{Vagal reflex during bronchoconstriction}

Inhalation of saline solution in the bronchial side had no effect on the bronchial musculature and the other parameters measured. Typical responses of ventilation overflow and intratracheal pressure to inhalation of a $0.00125 \%$ solution of histamine for $10 \mathrm{~min}$ to the bronchial side are shown in Fig. 1. Histamine inhalation induced an increase in intratracheal pressure, viz., reflex tracheal constriction following an increase in ventilation overflow, viz., bronchoconstriction. The reflex tracheal constriction occurred after a time lag following the bronchoconstriction. Both the reflex tracheal constriction and bronchoconstriction showed the maximum response near the end of histamine inhalation, and therefore, together with the end of inhalation, they showed a gradual recovery. An infusion of 5 $\mu \mathrm{g} / \mathrm{min}$ of atropine to the tracheal site
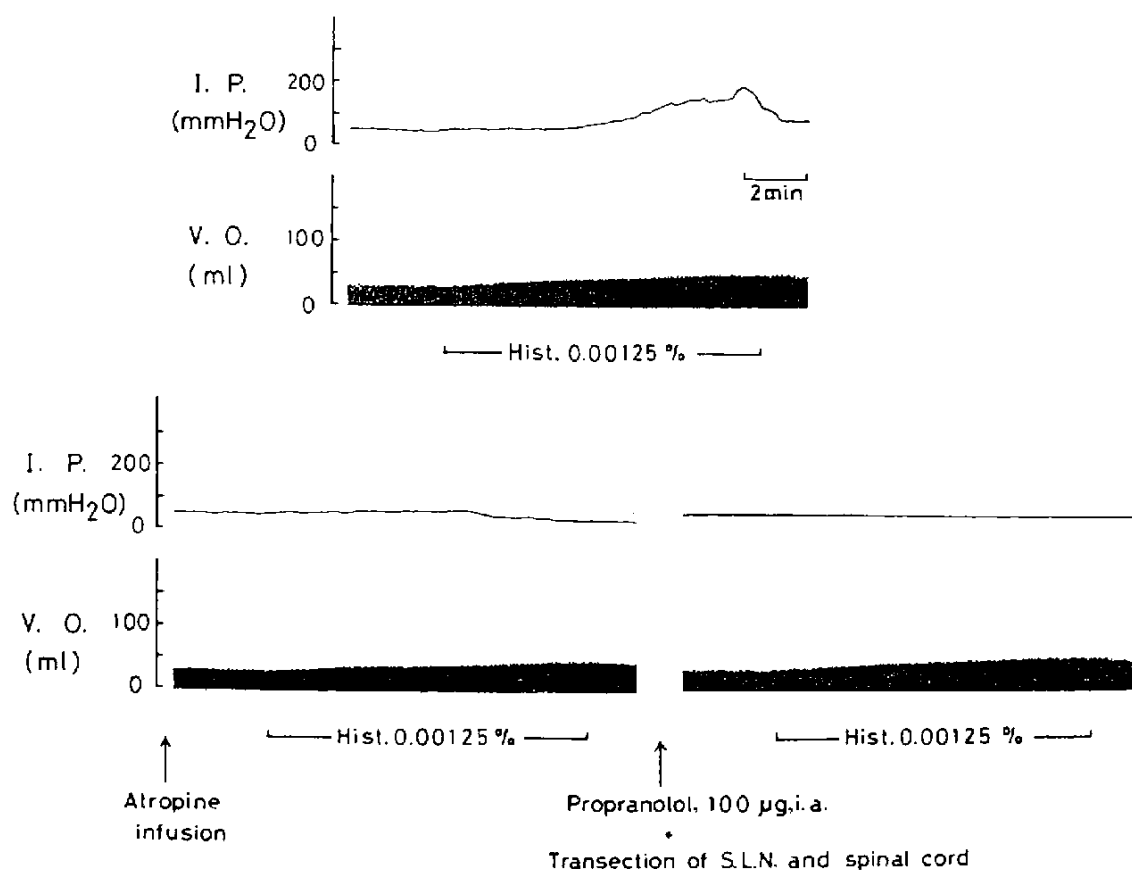

Fig. 1. Responses of intratracheal pressure (I.P.) and ventilation overflow (V.O.) to histamine (Hist.) inhalation for $10 \mathrm{~min}$ during i.a. atropine $(5 \mu \mathrm{g} / \mathrm{min})$ infusion, i.a. propranolol injection and transections of both the bilateral superior laryngeal nerves (S.L.N.) and the spinal cord at the $C_{1}$ level. 
changed the reflex tracheal constriction by histamine inhalation into a tracheal dilatation (Figs. 1 and $2(A)$ ). The reflex dilatation occurred after a time lag following bronchoconstriction and recovered with the disappearance of bronchoconstriction. The basal tonus of the bronchial musculature and the bronchial constriction induced by histamine inhalation were unaffected by the atropine infusion. The mag-
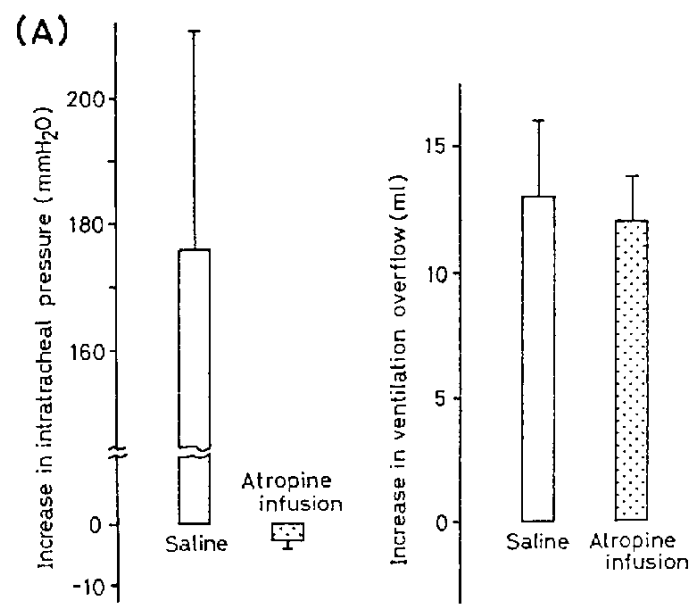

(B)

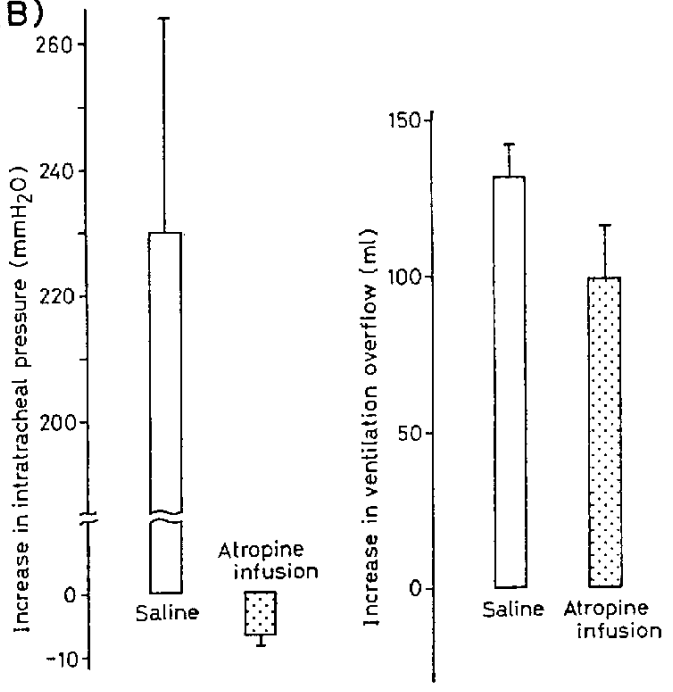

Fig. 2. Effects of i.a. atropine $(5 \mu \mathrm{g} / \mathrm{min})$ infusion on the increases in intratracheal pressure (left side) and ventilation overflow (right side) induced by $0.00125 \%$ histamine inhalation (A) or Ascaris antigen ( $3 \mathrm{mg}$ protein) inhalation (B). Each column is the mean value with S.E. for six to seven experiments. nitude of the dilatation was smaller than that of the reflex tracheal constriction. The reflex tracheal dilatation in the presence of atropine was abolished by the combination of $100 \mu \mathrm{g}$ propranolol and transections of both the bilateral superior laryngeal nerves and the spinal cord at the $\mathrm{C}_{1}$ level (Fig. 1).

Ascaris suum antigen inhalation for $10 \mathrm{~min}$ ( $3 \mathrm{mg}$ protein) to naturally sensitized dogs caused a reflex tracheal constriction. The bronchoconstriction and reflex tracheal constriction induced by antigen inhalation were more potent than those by histamine inhalation. The bronchoconstriction showed the maximum response near the end of antigen inhalation, whereas the reflex tracheal constriction tended to recover during the antigen inhalation. With the atropine infusion at a rate of $5 \mu \mathrm{g} / \mathrm{min}$ to the tracheal site, the reflex tracheal dilatation was induced by the antigen inhalation (Fig. 2). The reflex dilatation recovered with the disappearance of bronchoconstriction. This reflex dilatation was abolished by the combination of $100 \mu \mathrm{g}$ propranolol and transections of both the bilateral superior laryngeal nerves and the spinal cord at the $C_{1}$ level as in the case of histamine inhalation.

\section{Intervention of inhibitory nerves in the reflex} tracheal constriction

The reflex tracheal constriction induced by $0.00125 \%$ histamine inhalation was significantly increased with an application of $100 \mu \mathrm{g}$ propranolol to the tracheal site. Furthermore, the reflex tracheal constriction was further enhanced by the combination of $100 \mu \mathrm{g}$ propranolol and transection of the spinal cord at the $\mathrm{C}_{1}$ level. On the other hand, the bronchoconstriction induced by histamine inhalation was unaffected by $100 \mu \mathrm{g}$ propranolol and transection of the spinal cord at the $\mathrm{C}_{1}$ level (Fig. 3(A)).

The reflex tracheal constriction induced by antigen inhalation also tended to increase by $100 \mu \mathrm{g}$ propranolol and transection of the spinal cord at the $C_{1}$ level, while the bronchoconstriction by the antigen inhalation was unaffected as in the case of histamine inhalation (Fig. 3(B)). 
(A)
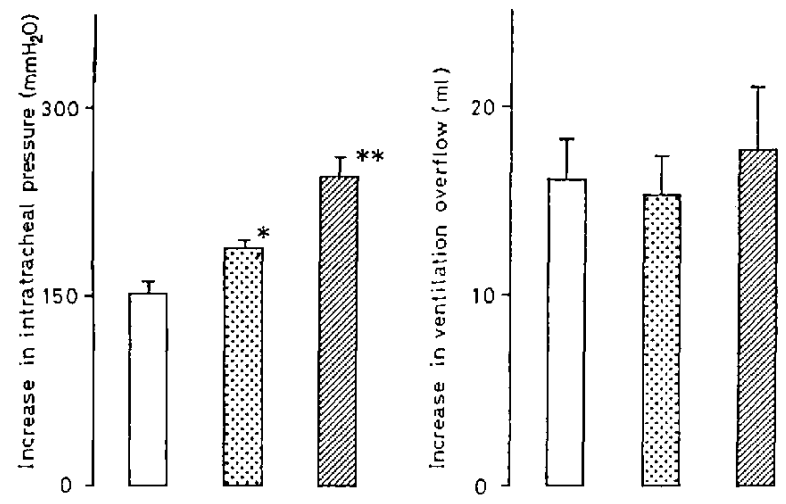

(B)

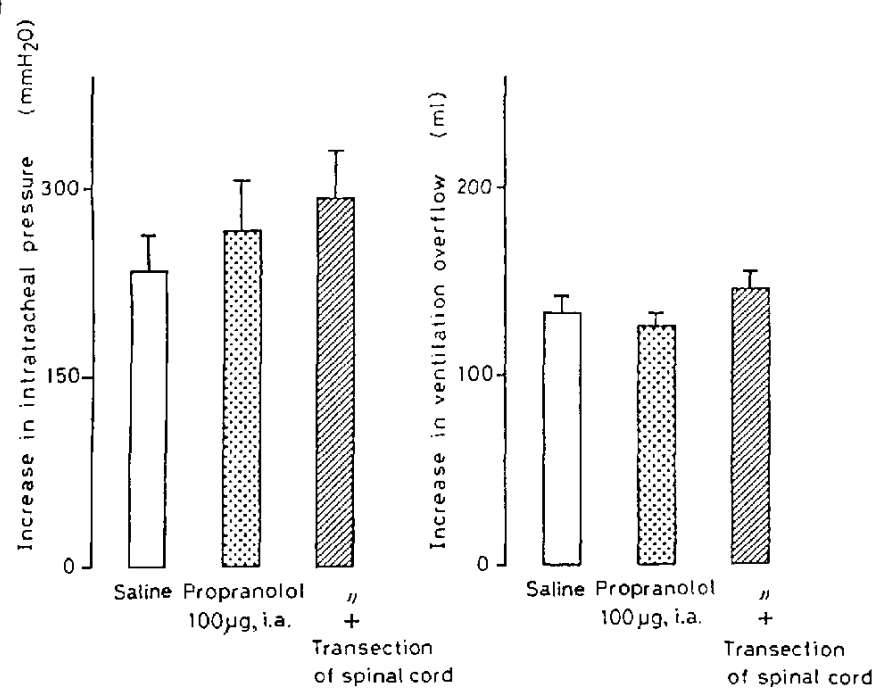

Fig. 3. Effects of propranolol i.a. and transection of the spinal cord together with propranolol i.a. on the tracheal and bronchial constrictions induced by $0.00125 \%$ histamine inhalation (A) or Ascaris antigen (3 mg protein) inhalation (B). Each column is the mean value with $S$.E. for five to seven experiments. The changes are significant at ${ }^{*} \mathrm{P}<0.05$ and ${ }^{*} \mathrm{P}<0.01$ against the saline control.

\section{DISCUSSION}

We previously devised a preparation for evaluating the vagal reflex-induced tracheal response (10). In the present study, using this preparation, it was observed that the inhalation of histamine aerosol into the bronchial site caused a bronchoconstriction followed by a reflex tracheal constriction. The reflex tracheal constriction was also observed during the inhalation of Ascaris suum antigen. The antigen-induced bronchoconstriction was re- duced by vagotomy or vagal blockade with nerve cooling $(7,9)$. The present observation of the reflex component induced by antigen inhalation may indicate a prominent role of the vagal reflex in asthmatic airway constriction.

The reflex tracheal constriction induced by histamine inhalation was changed into a tracheal dilatation by atropine infusion to the tracheal site, indicating that not only the reflex tracheal constriction but also reflex dilatation, which is usually masked by constriction, 
may occur simultaneously. It has been reported that stretch receptors induce a reflex relaxation of airway smooth muscle (14). Bartlett et al. (13) demonstrated that the activities of stretch receptors increased during airway constriction. Thus, it is indicated that airway stretch receptors may play a role in a mechanism limiting bronchoconstriction (14). Therefore, the reflex tracheal dilatation during bronchoconstriction induced by histamine or antigen inhalation may result from activation of stretch receptors in the bronchi.

The reflex tracheal dilatation induced by antigen inhalation was more potent than that by histamine inhalation. This discrepancy seems to come from the difference in the degree of the reflex tracheal constriction following bronchoconstriction, because the antigen inhalation may release various chemical mediators.

In the present study, we observed that the antigen-induced reflex tracheal constriction tended to recover during the antigen inhalation. Thus, there is no clear difference in the recovery of the reflex constriction between the histamine and antigen inhalations. Although the reason for this result is not clear at present one possible explanation is that the recovcry may be related to the strength of the reflex tracheal dilatation. In the case of histamine inhalation, it may be thought that reflex tracheal dilatation was small and was not sufficient to lead to restoration of tracheal constriction during the inhalation.

The reflex dilatation was abolished by tho combination of propranolol and transections of both the bilateral superior laryngeal nerves and the spinal cord at the $\mathrm{C}_{1}$ level. It has been demonstrated that the canine tracheal smooth muscle is dilated by sympathetic neuronal stimulation $(20,21)$ and that the activation of sympathetic nerves reduces histamine-induced tracheal constriction (22). Thus, the sympathetic neuronal pathway is considered as one of the inhibitory nervous systems on the canine trachea. In addition, a previous study has shown the possible involvement of nonadrenergic nerves, as an efferent pathway other than sympathetic nerves, which run in the bilateral superior laryngeal nerves and the spinal cord in reflex tracheal dilatation caused by lung inflation (17). It has been demonstrated that airway stretch receptors respond to both positive and negative transmural pressure $(23,24)$, and pulmonary stretch receptors are well-known to be stimulated by lung inflation. Therefore, sympathetic and nonadrenergic nerves on the trachea may mediate the reflex tracheal dilatation caused by histamine- or antigen-induced bronchoconstriction as well as that caused by lung inflation. In the present study, the quantitative ratio of the involvements of sympathetic and nonadrenergic nerves in the reflex dilatation could not be estimated because the experiment with a blockade of nonadrenergic nervous system was not done.

The reflex tracheal constriction induced by histamine inhalation was potentiated by propranolol. Diamond (25) showed a potentiation of the bronchomotor response to histamine by $\beta$-adrenergic antagonists. McCulloch ct al. (16) found evidence for a sympathetic bronchodilator reflex following bronchoconstriction induced by histamine. Therefore, the sympathetic nervous system in the trachea may serve to attenuate the reflex tracheal constriction induced by histamine inhalation. Because the tracheal constriction by Ascaris stum antigen inhalation also tended to be enhanced by an application of propranolol, this kind of sympathetic nerves-mediated inhibitory tracheal reflex response might also occur during asthmatic bronchoconstriction. Furthermore, the reflex tracheal constriction induced by histamine or antigen inhalation under $\beta$-blockade was further potentiated by transection of the spinal cord. These results suggest that nonadrenergic nerves contained in preganglionic sympathetic nerves (11) may also limit the reflex tracheal constriction.

On the other hand, the bronchoconstriction induced by histamine or antigen inhalation was nol enhanced by a treatment with propranolol or transection of the spinal cord. Because propranolol was applied locally to the 
tracheal site in this study, enhancement of the bronchoconstriction by $\beta$-blockade was not observed. Since McCulloch et al. (16) demonstrated a potentiation of histamine-induced bronchoconstriction by propranolol in dogs, it is presumed that sympathetic nerves reflexly counteract not only tracheal constriction but also bronchoconstriction through the activation of $\beta$-adrenoceptors. Furthermore, the bronchoconstriction by histamine or antigen inhalation was also not affected by transection of the spinal cord. It is indicated that nonadrenergic nerves may have much less involvement in the bronchoconstriction than in the tracheal constriction. Probably, the inhibitory reflex mediated by nonadrenergic nerves may be masked by the bronchoconstriction so that histamine and antigen caused a very potent bronchoconstrictions.

In both experiments of histamine and antigen inhalations, potentiations of reflex tracheal constriction induced by $\beta$-blockade and transection of spinal cord together with $\beta$ blockade werc larger than the reflex dilatation under atropine infusion. Therefore, it may be speculated that first, because prejunctional $\beta_{2}$ receptors inhibit acetylcholine release from cholinergic nerve endings (26), propranolol cnhances the release in the trachea; and second, $\alpha$-mediated tracheal constrictions appeared by $\beta$-blockade (27).

In conclusion, during histamine- or antigeninduced bronchoconstriction, the reflex tracheal dilatation which is thought to be mediated by the sympathetic nervous system and partly by the nonadrenergic nervous system may occur simultaneously with the reflex tracheal constriction. The inhibitory reflex response may thus play a role in a mechanism limiting the airway constriction.

\section{REFERENCFS}

1 DeKock, M.A., Nadel, J.A., Zwi, S., Colebatch, H.J.H. and Olsen, C.R.: New method for perfusing bronchial arteries: histamine bronchoconstriction and apnea. J. Appl. Physiol. 21, 185-194 (1966)
2 Karczewski, W. and Widdicombe, J.G.: 'lhe role of the vagus nerves in the respiratory and circulatory responses to intravenous histamine and phenyl diguanide in rabbits. J. Physiol. (Lond.) 201, $271-291$ (1969)

3 Mills, J.E. and Widdicombe, J.G.: Role of the vagus nerves in anaphylaxis and histamine-induced bronchoconstrictions in guinca-pigs. Br. J. Pharmacol. 39, 724-731 (1970)

4 Yu, D.Y.C., Galant, S.P. and Gold, W.M.: Inhibition of antigen-induced bronchoconstriction by atropine in asthmatic patients. J. Appl. Physiol. 32, $823-828$ (1972)

5 Gold, W.M., Kessler, G.-F. and Yu, D.Y.C.: Role of vagus nerves in experimental asthma in allergic dogs. J. Appl. Physiol. 33, $719-725$ (1972)

6 Drazen, J.M. and Austen, K.F.: Pulmonary responses to antigen infusion in the sensitized guinea pig: Modification by atropine. J. Appl. Physiol. 39, 916-919 (1975)

7 Yamatake, Y., Sasagawa, S., Yanaura, S. and Kobayashi, N.: Allergy induced asthma with ascaris sum administration to dogs. Japan. J. Pharmacol. 27, 285-293 (1977)

8 Yanaura, S., Goto, K., Kitagawa, H., Hosokawa, T., Misawa, M., Kobayashi, N. and Hayakawa, H.: Role of yagus nerves in bronchoconstriction induced by chemical mediators. Folia Pharmacol. Japon. 79, 571 - 579 (1982) (Abs. in English)

9 Yanaura, S., Mizuno, H., Goto, K., Kamei, J., Hosokawa, T., Ohtani, K. and Misawa, M.: Effects of 8-(2-fluoroethyl)-3 $\alpha$-hydroxy-1 $\alpha \mathrm{H}, 5 \alpha \mathrm{H}$ tropaniumbromide benzilate (Ba598Br) on allergyand drug-induced asthmas. Japan. J. Pharmacol. $33,971-982$ (1983)

10 Hosokawa, T., Goto, K., Kamei, J., Ohtani, K., Misawa, M. and Yanaura. S.: Analysis of the vagal reflex tracheal constriction in the $\operatorname{dog}$. Japan. J. Pharmacol. 36, $241-248$ (1984)

11 Karczewski, W. and Widdicombe, J.G.: The effect of vagotomy, vagal cooling and efferent vagal stimulation on breathing and lung mechanics of rabbits. I. Physiol. (Lond.) 201, 259-270 (1969)

12 Coleridge, J.C.G., Coleridge, H.M., Roberts, A.M., Kaufman, M.P. and Baker, D.G.: Trachcal contraction and relaxation initiated by lung and somatic afferents in dogs. J. Appl. Physiol. 52, $984-990(1982)$

13 Bartlett, D., Jr., Jeffery, P., Sant-Ambrogio, G. and Wise, J.C.M.: Location of stretch receptors in the trachea and bronchi of the dog. J. Physiol. (Lond.) 258, 409-420 (1976)

14 Widdicombe, J.G. and Nadel, J.A.: Reflex effects of lung inflation on tracheal volume. J. Appl. 
Physiol. 18, 681-686 (1963)

15 Cabezas, G.A., Graf, P.D, and Nadel, J.A.: Sympathetic versus parasympathetic nervous regulation of airways in dogs. J. Appl. Physiol. 31, $651-655$ (1971)

16 McCulloch, M.W., Proctor, C. and Rand, M.J.: Evidence for an adrenergic homeostatic bronchodilator reflex mechanism. Eur. J. Pharmacol. 2, 214-223 (1967)

17 Misawa, M., Takahashi, Y., Hosokawa, T. and Yanaura, S.: Involvement of inhibitory innervation in reflex tracheal dilatation induced by lung inflation. Japan. J. Pharmacol. 52, 639-642 (1990)

18 Konzett, H. and Rössler, R.: Versuchsanordnung zu Untersuchungen an der Bronchialmuskulatur. (Experimental method for investigating bronchial musculature.) Arch. Exp. Pathol. Pharmakol. 195. $71-74$ (1940) (in German)

19 Yanaura, S., Hosokawa, T., Kitagawa, H. and Yamatake, Y.: Influence of tracheal muscular tone on the initiation of cough reflex. Japan. J. Pharmacol. 28, $447-455$ (1978)

20 Castro de la Mata, R., Penna, M. and Aviado, D.M.: Reversal of sympathomimetic bronchodilation by dichloroisoproterenol. J. Pharmacol. Exp. Ther. 135, 197-203 (1962)
21 Kannan, M.S. and Daniel, E.E.: Structural and functional study of control of canine tracheal smooth muscle. Am. J. Physiol. 238, C27-C33 (1980)

22 Leff, A.R., Munoz, N.M. and Hendrix, S.G.: Sympathetic inhibition of histamine-induced contraction of canine trachealis in vivo. J. Appl. Physiol. 53, 21-29 (1982)

23 Widdicombe, J.G.: Receptors in the trachea and bronchi of the cat. J. Physiol. (Lond.) 123, $71-104$ (1954)

24 Bartlett, D., Jr., Sant-Ambrogio, G. and Wise, J.C.M.: Transduction properties of tracheal stretch receptors. J. Physiol. (Lond.) 258, $421-432$ (1976)

25 Diamond, L.: Potentiation of bronchomotor responses by beta adrenergic antagonists. J. Pharmacol. Exp. Ther. 181, 434-445 (1972)

26 Rhoden, K.J., Meldrum, L.A. and Barnes, P.J.: Inhibition of cholinergic neurotransmission in human airways by $\beta_{2}$-adrenoceptors. J. Appl. Physiol. 65, 700-705 (1988)

27 Himori, N. and Taira, N.: A method for recording smooth muscle and vascular responses of the blood-perfused dog trachea in situ. Br. J. Pharmacol. 56, 293-299 (1976) 